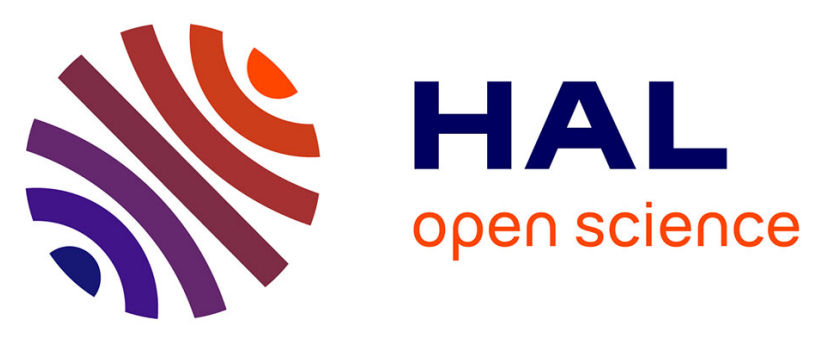

\title{
Effect of changes in dietary net energy concentration on growth performance, fat deposition, skatole production, and intestinal morphology in immunocastrated male pigs
}

Nina Batorek-Lukač, Marjeta Čandek-Potokar, Martin Škrlep, Valentina Kubale, Etienne Labussière

\section{To cite this version:}

Nina Batorek-Lukač, Marjeta Čandek-Potokar, Martin Škrlep, Valentina Kubale, Etienne Labussière. Effect of changes in dietary net energy concentration on growth performance, fat deposition, skatole production, and intestinal morphology in immunocastrated male pigs. Frontiers in Veterinary Science, 2021, 8, pp.789776. 10.3389/fvets.2021.789776 . hal-03522335

\section{HAL Id: hal-03522335 \\ https://hal.inrae.fr/hal-03522335}

Submitted on 12 Jan 2022

HAL is a multi-disciplinary open access archive for the deposit and dissemination of scientific research documents, whether they are published or not. The documents may come from teaching and research institutions in France or abroad, or from public or private research centers.
L'archive ouverte pluridisciplinaire HAL, est destinée au dépôt et à la diffusion de documents scientifiques de niveau recherche, publiés ou non, émanant des établissements d'enseignement et de recherche français ou étrangers, des laboratoires publics ou privés. 
OPEN ACCESS

Edited by:

Giovanna Martelli,

Università di Bologna, Italy

Reviewed by:

Carolina Pugliese,

University of Florence, Italy Cesar Augusto Pospissil Garbossa,

University of São Paulo, Brazi

Danijel Karolyi,

University of Zagreb, Croatia

*Correspondence:

Nina Batorek-Lukač nina.batorek@kis.si

Specialty section:

This article was submitted to Animal Nutrition and Metabolism,

a section of the journal

Frontiers in Veterinary Science

Received: 05 October 2021 Accepted: 16 November 2021 Published: 14 December 2021

Citation:

Batorek-Lukač N, Čandek-Potokar M, Škrlep M, Kubale $V$ and Labussière $E$ (2021) Effect of Changes in Dietary Net Energy Concentration on Growth Performance, Fat Deposition, Skatole Production, and Intestinal Morphology in Immunocastrated Male Pigs. Front. Vet. Sci. 8:789776. doi: 10.3389/fvets.2021.789776

\section{Effect of Changes in Dietary Net Energy Concentration on Growth Performance, Fat Deposition, Skatole Production, and Intestinal Morphology in Immunocastrated Male Pigs}

\author{
Nina Batorek-Lukač ${ }^{1 *}$, Marjeta Čandek-Potokar ${ }^{1}$, Martin Škrlep ${ }^{1}$, Valentina Kubale ${ }^{2}$ and \\ Etienne Labussière ${ }^{3}$
}

${ }^{1}$ Agricultural institute of Slovenia, Animal Production Department, Ljubljana, Slovenia, ${ }^{2}$ Veterinary Faculty, Institute of Preclinical Sciences, University of Ljubljana, Ljubljana, Slovenia, ${ }^{3}$ PEGASE, INRAE, Institut Agro, Saint Gilles, France

Nutritional requirements of heavy immunocastrated (IM) pigs and therefore appropriate feeding strategies have not yet been determined. Thus, the effects of changes in dietary net energy (NE) content were studied in $41 \mathrm{IM}$ pigs, fed ad libitum diets with low, medium, and high NE content (LNE, MNE, and HNE diets, with 8.5, 9.3, and 10.0 MJ NE/kg, respectively), from 84 days of age until slaughter at an average age of 172 days and an average body weight of $122.5 \mathrm{~kg}$. In the period from 143 to 170 days of age, there was a tendency for a greater NE intake $(p=0.08)$ in pigs fed the HNE diet along with greater $(p<0.01)$ backfat gain. Dietary treatment affected carcass composition, as lower backfat thickness $(p=0.01)$ and lower area of fat over the longissimus muscle $(p=0.05)$ were observed in the LNE and MNE pigs. In addition, greater lean meat content $(p=0.04$ ) was observed in the LNE pigs. Reducing the NE of the diet by replacement of cereals and soybean meal with high-fiber ingredients resulted in lower indole production in the ascending colon $(p<0.01)$ and greater skatole production $(p<0.01)$ in the cecum. Greater villus area, width, height and perimeter, crypt depth, and thickness of the intestinal mucosa in the jejunum, ileum, ascending colon, and descending colon were found in the LNE group $(p<0.01)$ than in the HNE group, while those in the MNE group was intermediate. Cell proliferation was not affected by dietary treatment $(p>0.05)$. The present results show that a reduction in dietary NE concentration lowers lipid deposition, without affecting performance or energy efficiency in IM pigs. This technique provides an advantage in terms of improved leanness, without affecting growth rate in IM pigs after immunization, which is particularly important when the backfat thickness is a determinant of carcass value and IM pigs are fattened to higher weights (e.g., in heavy pig production) or when a longer delay between immunization and slaughter is practiced.

Keywords: immunocastration, precision feeding, dietary fiber, leanness, energy reduction, porc 


\section{INTRODUCTION}

In many countries, male piglets are still surgically castrated shortly after birth as a preventive measure against the development of boar taint. Lately, the vaccination against gonadotropin-releasing hormone (i.e., immunocastration) has been proposed as an alternative to surgical castration that improves animal welfare and allows to benefit from lean tissue growth and feed efficiency of entire males (EM) for most of the growing period (1). When standard immunization protocols are used, the physiological effects of immunocastration become evident as early as 1 week after effective immunization [i.e., after applying the second dose of vaccine (2)]. However, after effective immunization, a substantial increase in daily feed intake (DFI) is observed in immunocastrated (IM) pigs, resulting in reduced feed efficiency and increased body fatness as compared with $\operatorname{EM}(3,4)$. These negative consequences can be limited either by restricting feed allowance after immunization (5) or by shortening the time interval between immunization and slaughter, which gives pigs less time to deposit fat (6). Quantitative feed restriction has been shown to improve the performance of IM pigs (5) but may also stimulate aggressive behavior and increase the level of stress $(5,7)$, raising questions about welfare degradation. As an alternative, a reduced energy concentration of the ad libitum diet may be considered. Since the energy component of the feed accounts for most of the cost in pork production (8), replacing energy-rich starch from cereals with relatively inexpensive fibrous feedstuffs, such as cereal byproducts, in the finishing diet may be of interest for IM pigs. Additionally, dietary fiber may be beneficial for physiological function and gastrointestinal health (9). Immunocastration has been shown to effectively prevent the accumulation of boar taint compounds (androstenone and skatole) in adipose tissue by reducing steroid hormones synthesis in the testes and also by preventing the inhibition of skatole degradation by steroids in the liver (10). However, skatole production in the intestine is influenced by numerous other factors including housing conditions (11), animal health (12), and dietary composition $(13,14)$. Namely, by influencing the rate of apoptosis, diet can alter the availability of L-tryptophan, the precursor of skatole, in the colon and thus can affect skatole production, while skatole absorption can be reduced by accelerating the intestinal transit time $(13,14)$.

Limiting (excessive) fat deposition after immunocastration by dietary measures may become a key factor for the economic sustainability of this alternative especially when pigs are slaughtered at a greater age and weight (e.g., in special production systems). Hence, the objective of this study was to evaluate the effect of net energy (NE) concentration of the feed given to IM

Abbreviations: ADF, acid detergent fiber; ADFI, average daily feed intake; ADG, average daily gain; BFT, backfat thickness; BW, body weight; CP, crude protein; DE, digestible energy; DFI, daily feed intake; DM, dry matter; EM, entire males; Exp.1, experiment 1; Exp. 2, experiment 2; G:F, gain to feed ratio; G:NE, gain to net energy ratio; GE, gross energy; HCW, hot carcass weight; HNE, high net energy; IM, immunocastrated pigs; LNE, low net energy; ME, metabolizable energy; MNE, medium net energy; NDF, neutral detergent fiber; NE, net energy; OM, organic matter; SCFA, short-chain fatty acid; V1, first vaccination; V2, second vaccination. pigs during the prolonged period between effective vaccination and slaughter on growth performance, fat deposition, skatole production, intestinal morphology, and cell proliferation.

\section{MATERIALS AND METHODS}

\section{Animals and Experimental Design}

As presented in Figure 1, the study included an experiment on informative digestibility and nitrogen balance (Exp. 1) and a growth experiment (Exp. 2). The experiments aimed to compare the utilization by IM pigs of three cereal-based diets differing in their NE content (Table 1). To this end, the NE content was reduced from $10.0 \mathrm{MJ} / \mathrm{kg}$ in the high $\mathrm{NE}$ diet (HNE) to 9.3 and $8.5 \mathrm{MJ} / \mathrm{kg}$ in the medium NE (MNE) and low NE (LNE) diets, respectively, by substitution of cereals (wheat, barley, and corn) and soybean meal with high-fiber ingredients (wheat bran, soybean hulls, and dried beet pulp) and reduction of the amount of added sunflower oil. The MNE diet was calculated as the mean composition of HNE and LNE diets.

\section{Experiment 1}

To accurately calculate the NE content (8), a digestibility and nitrogen balance study was conducted with 4 IM pigs (Improvac ${ }^{\circledR} 2 \mathrm{ml}$, subcutaneous application at 77 and 105 days of age, Zoetis Florham Park, NJ, USA). Pigs [Piétrain $\times$ (Large White $\times$ Landrace)] were housed individually in digestibility cages and fed the two extreme experimental diets (i.e., HNE and LNE) for two consecutive periods, such that there were two pigs per diet in each period. Each period consisted of an adaptation sub-period (14 days, allowing pigs to adapt to the feed, digestibility cage, and environmental conditions) and a subsequent total collection sub-period (7 days), during which feed intake was recorded and feces and urine were separately collected. Pigs were weighed at the beginning (at 77 days of age) of the trial and at the beginning and the end of each collection sub-period. During the collection period, feed allowance was restricted to $90 \%$ of predicted ad libitum NE intake [calculated according to INRA Porc software (16)]. Water was freely available. Pelleted feed was prepared daily and distributed in equal amounts 3 times per day $(09: 00,12: 00$, and 15:00), whereas feed residues were collected each morning and stored at $4{ }^{\circ} \mathrm{C}$ until analysis of dry matter (DM; $24 \mathrm{~h}$ in a ventilated oven at $103^{\circ} \mathrm{C}$ ). A representative sample of each diet was collected during the collection period and stored at $4^{\circ} \mathrm{C}$ until analysis of DM and chemical composition. During the collection period, feces and urine (collected in a 10-L plastic container with $120 \mathrm{ml}$ of $10 \%$ sulfuric acid) were collected each morning. Feces were stored at $4^{\circ} \mathrm{C}$ and accumulated during the collection period. On the day following the last collection, total collected feces were weighed and homogenized. Three representative samples were taken, two of which were dried for $48 \mathrm{~h}$ at $100^{\circ} \mathrm{C}$ for determination of $\mathrm{DM}$, while the third sample was freeze-dried, ground (1-mm grind), and stored at $4^{\circ} \mathrm{C}$ until further laboratory analyses. The containers for urine collection were changed every morning, and the $\mathrm{pH}$ was measured and, if necessary, adjusted by adding $10 \%$ sulfuric acid, so that the value was below 2.0. Afterward, urine was weighed and homogenized, and a representative sample (1\%) 


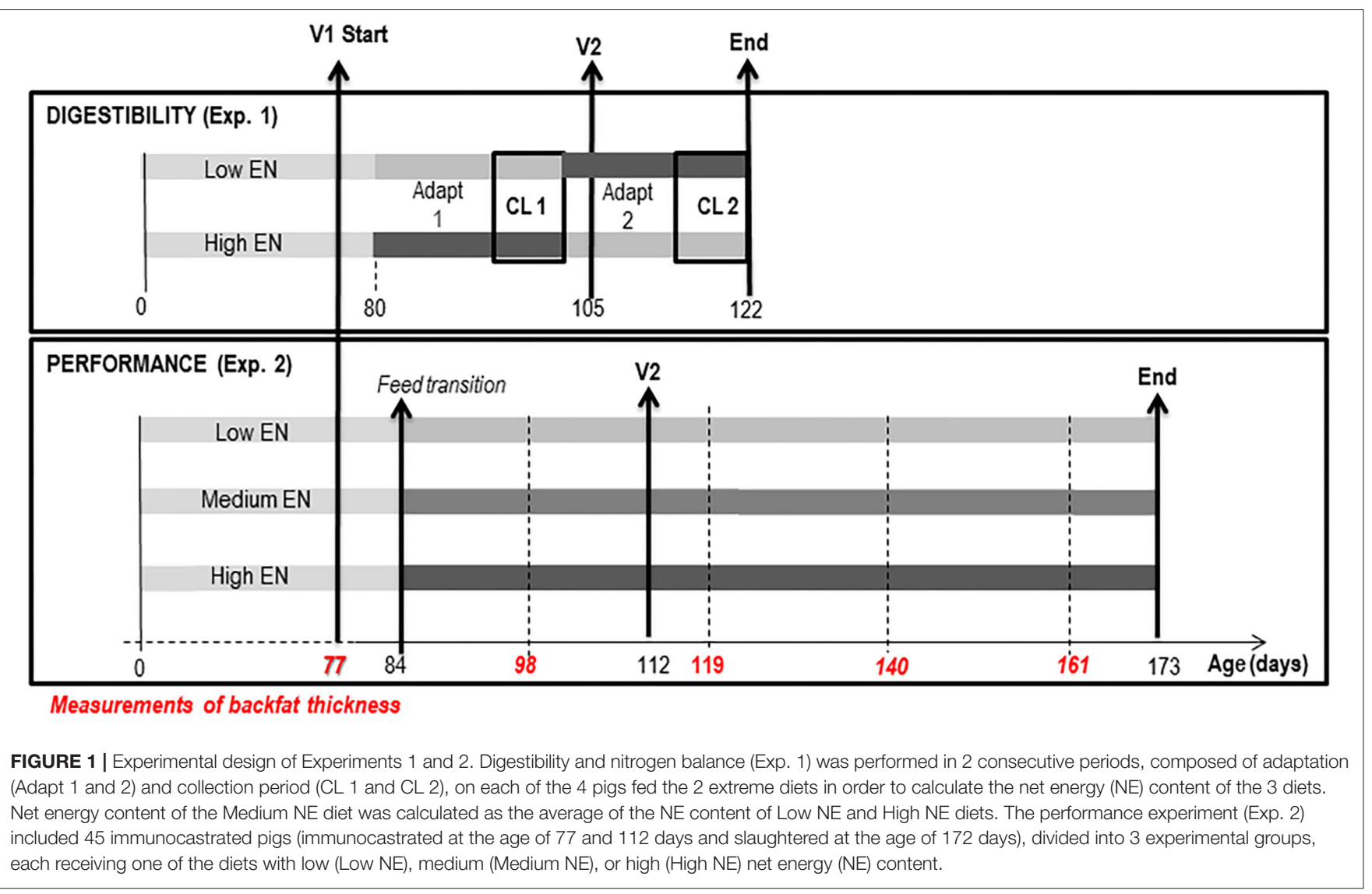

was taken, cumulated over the entire collection period, and stored at $4^{\circ} \mathrm{C}$.

\section{Experiment 2}

At 70 days of age, 45 male piglets [Piétrain $\times$ (Large White $\times$ Landrace)] from 12 different litters were transferred to the experimental stables (individual housing, concrete floor, and water freely available) and fed a commercial growing diet until the start of the experiment. Two vaccinations with Improvac ${ }^{\circledR}$ ( $2 \mathrm{ml}$, subcutaneous application, Zoetis Florham Park, NJ, USA) were given at 77 and 112 days of age. At 84 days of age, the pigs (within the litter) were allocated to 3 groups of 15 animals receiving one of the experimental diets (i.e., HNE, MNE, and LNE) in pelleted form, with a progressive transition that lasted for 5 days. During the experiment, pigs were fed individually 3 times per day at 09:00, 12:00, and 15:00 (manual feeding in the individual trough). Daily meals were prepared in buckets containing the expected ad libitum feed intake for 3 or 4 days plus $10 \%$ [calculated according to INRA Porc software (16)]. At the end of each 3- or 4-day period, accumulated feed refusals were collected and weighed. Feed refusals were not contaminated by urine or saliva and were therefore not dried, and their DM content was considered as for the offered feed, which was measured at each feed preparation.

Pigs were weighed weekly at the same time in the morning, without prior limitation of feed allowance. Ultrasound measurements (Noveko, VetkoPlus, 3.5 MHz) of the backfat thickness (BFT) at the level of the last rib (measured on the left and right sides of the back, $6 \mathrm{~cm}$ lateral to the spine and subsequently averaged per pig) were performed every 3 weeks from the first vaccination (V1) onwards to obtain 5 consecutive measurements on each animal during the experiment. The difference in BFT divided by the number of days elapsed between the corresponding measurements was calculated to assess the daily backfat gain in the total and interim periods.

Pigs were slaughtered (at an average age of 172 days) in two batches, balanced according to experimental groups and litter of origin, within a week in the experimental slaughterhouse of INRAE Saint-Gilles following standard slaughter procedures (approximately $20 \mathrm{~h}$ of feed withdrawal, electrical stunning, and immediate vertical bleeding). At evisceration, samples of the duodenum (at the caudal end of the pancreas), jejunum (the middle part), ileum ( $10 \mathrm{~cm}$ anterior to the ileocecal valve), cecum (the second haustrum distal to the apex), ascending colon (the top of the spiral colon), and descending colon $(30 \mathrm{~cm}$ from the end of the intestine) were collected and stored in 5\% buffered formalin. At the same time, the intestinal contents from the cecum, ascending colon, and descending colon were collected, immediately frozen in liquid nitrogen, and stored at $-20^{\circ} \mathrm{C}$ until analysis. At the end of the slaughter line, hot carcass weight (HCW) was recorded, and testicles were removed, dissected, and weighed. The weight of both testicles (including epididymis) 
TABLE 1 | Ingredients and chemical composition of experimental diets fed to immunocastrated male pigs.

\begin{tabular}{|c|c|c|c|}
\hline \multirow[b]{2}{*}{ Item } & \multicolumn{3}{|c|}{ Diet $^{a}$} \\
\hline & LNE & MNE & HNE \\
\hline \multicolumn{4}{|l|}{ Ingredient composition (\%) } \\
\hline Wheat & 17.77 & 21.35 & 24.93 \\
\hline Corn & 17.77 & 21.35 & 24.93 \\
\hline Barley & 17.77 & 21.35 & 24.93 \\
\hline Wheat bran & 15.00 & 8.75 & 2.50 \\
\hline Soybean hulls & 10.00 & 5.00 & - \\
\hline Dried beet pulp & 5.00 & 2.50 & - \\
\hline Soybean meal & 9.18 & 12.46 & 15.74 \\
\hline Rapeseed meal & 1.97 & 0.99 & - \\
\hline Cane molasses & 3.00 & 3.00 & 3.00 \\
\hline Sunflower oil & - & 0.50 & 1.00 \\
\hline I-Lysine $\mathrm{HCl}$ & 0.24 & 0.27 & 0.29 \\
\hline I-Threonine & 0.07 & 0.08 & 0.09 \\
\hline I-Tryptophan & 0.01 & 0.01 & 0.02 \\
\hline dl-Methionine & 0.01 & 0.02 & 0.03 \\
\hline I-Valine & - & 0.01 & 0.02 \\
\hline Sodium chloride & 0.45 & 0.45 & 0.45 \\
\hline Limestone & 0.29 & 0.41 & 0.54 \\
\hline Dicalcium phosphate & 0.97 & 1.00 & 1.03 \\
\hline Vitamins-minerals premix ${ }^{b}$ & 0.50 & 0.50 & 0.50 \\
\hline \multicolumn{4}{|c|}{ Measured chemical composition, $\mathrm{g} / \mathrm{kg}$ of DM } \\
\hline Ash & 60 & 56 & 54 \\
\hline Crude protein $(\mathrm{N} \times 6.25)$ & 180 & 175 & 185 \\
\hline Starch & 416 & 470 & 518 \\
\hline Ether extract & 33 & 34 & 42 \\
\hline Crude fiber & 80 & 60 & 34 \\
\hline Neutral detergent fiber & 228 & 188 & 147 \\
\hline Acid detergent fiber & 100 & 74 & 44 \\
\hline GE, MJ/kg of DM & 18.17 & 18.17 & 18.31 \\
\hline \multicolumn{4}{|l|}{ Nutritional values ${ }^{c}$} \\
\hline $\mathrm{DE}, \mathrm{MJ} / \mathrm{kg}$ of feed & 12.24 & 13.00 & 13.89 \\
\hline $\mathrm{NE}, \mathrm{MJ} / \mathrm{kg}$ of feed & 8.50 & 9.25 & 9.99 \\
\hline SID lysine ${ }^{d}, \mathrm{~g} / \mathrm{kg}$ of feed & 7.1 & 7.8 & 8.4 \\
\hline SID threonine, $\mathrm{g} / \mathrm{kg}$ of feed & 4.6 & 5.0 & 5.4 \\
\hline SID tryptophan, $g / k g$ of feed & 1.4 & 1.5 & 1.8 \\
\hline SID methionine, $\mathrm{g} / \mathrm{kg}$ of feed & 2.0 & 2.3 & 2.6 \\
\hline SID valine, $g / k g$ of feed & 5.4 & 5.9 & 6.5 \\
\hline
\end{tabular}

Experimental diets were fed to immunocastrated male pigs between 84 and 172 days of age. Immunocastration with Improvac ${ }^{\circledR}(2 \mathrm{ml}$, s.c. application, Zoetis) was performed at the age of 77 and 112 days. DM, dry matter; GE, gross energy; DE, digestible energy; NE, net energy; SID, standardized ileal digestible. ${ }^{a}$ Diets with low (LNE), medium (MNE), or high (HNE) NE content. ${ }^{b}$ Supplied per kilogram of final diet (as-fed basis): vitamin A, 5,000 UI; vitamin D3, 1,000 Ul; vitamin E, $20 \mathrm{Ul}$; vitamin B1, $2 \mathrm{mg}$; vitamin B2, 4mg; pantothenic acid, $10 \mathrm{mg}$; vitamin B6, $1 \mathrm{mg}$; vitamin B12, $0.02 \mathrm{mg}$; niacin, $15 \mathrm{mg}$; vitamin $\mathrm{K} 3,2 \mathrm{mg}$; folic acid, $1 \mathrm{mg}$; biotin, $0.2 \mathrm{mg}$; choline chloride, $500 \mathrm{mg}$; iron, $80 \mathrm{mg}$; copper, $10 \mathrm{mg}$; zinc, $100 \mathrm{mg}$; magnesium, $40 \mathrm{mg}$; cobalt, $0.1 \mathrm{mg}$; iodine, $0.2 \mathrm{mg}$; selenium, $0.15 \mathrm{mg}$. ${ }^{c}$ Calculated from the feed ingredients according to Sauvant et al. (15), adjusted to $89 \%$ DM content of the diet. ${ }^{d}$ The SID lysine/NE ratio was constant among diets at a level of $0.84 \mathrm{~g} / \mathrm{MJ}$. was recorded for each pig. Leaf fat was excised from both halfcarcasses and weighed.

Carcasses were chilled overnight until the internal carcass temperature was below $7^{\circ} \mathrm{C}$. Additional carcass characteristics were assessed the following day. Intermuscular neck fat (percent), longissimus muscle area (square centimeters), and fat over longissimus muscle area (square centimeters) were assessed by image analysis on pictures of carcass cross sections taken between the 3rd and 4th cervical vertebrae (for evaluation of intermuscular neck fat) and after the last rib (for evaluation of longissimus muscle area and fat over longissimus muscle), as described by Batorek et al. (5).

Caudally from the level of the last rib, a $2.5-\mathrm{cm}$-thick slice of longissimus muscle was removed, vacuum-packed, and stored at $-20^{\circ} \mathrm{C}$ to determine intramuscular fat using NIRS (NIR System model 6,500 Spectrometer, Silver Spring, MD, USA) and in-house developed calibrations (Agricultural Institute of Slovenia). For determination of boar taint compounds, samples of subcutaneous fat were taken at the level of the last rib, vacuumpacked, and stored at $-20^{\circ} \mathrm{C}$ until further laboratory analyses.

\section{Chemical Analyses}

Pooled feed samples from Exp. 1 and 2 were analyzed for DM, ash, nitrogen, starch, crude fiber, and ether extract contents according to the Association of Official Analytical Chemists (AOAC) (17). Gross energy (GE) content was measured by an adiabatic bomb calorimeter (IKA, C5000, Staufen, Germany). The content of neutral detergent fiber (NDF) and acid detergent fiber (ADF) of pooled samples of diets was analyzed according to Van Soest et al. (18). Samples of feces from Exp. 1 were analyzed for DM, ash, nitrogen, crude fiber, ether extract with prior acid hydrolysis, NDF, ADF, and GE contents using the same methods as for feed samples. Fresh samples of urine from Exp. 1 were analyzed for nitrogen content, while the GE content was evaluated after freeze-drying of approximately $30 \mathrm{ml}$ of urine in polyethylene bags.

Androstenone and skatole concentrations were measured in subcutaneous fat samples from Exp. 2 by high-performance liquid chromatography (HPLC) (5) and expressed per gram of liquid fat. The detection limits were 0.24 and $0.03 \mu \mathrm{g} / \mathrm{g}$ for androstenone and skatole, respectively. Skatole and indole concentrations in intestinal content samples from Exp. 2 were measured by a modified method of Denhard et al. $(19,20)$. Concentrations were expressed per gram of sample, and the detection limit was $1.12 \mu \mathrm{g} / \mathrm{g}$ for skatole and indole.

\section{Histological and Immunohistochemical Evaluations of Intestinal Segments}

Tissue samples from the intestinal segments collected in Exp. 2 were embedded in paraffin, and histological sections $(5 \mu \mathrm{m}$ thick) were cut and stained with H\&E. Morphometric analysis was performed as described in detail by Bilič-Šobot et al. (21) using a Nikon Microphot FXA microscope equipped with a DSFil camera and the Imaging Software NIS Elements D.32 (Nikon Instruments Europe B.V., Badhoevedorp, The Netherlands). For each tissue sample of the small intestine, 20 villi and 20 crypts 
were examined at $\times 100$ magnification for villus width, villus height, villus perimeter, and crypt depth. Additionally, villus surface area, thickness of the intestinal mucosa, and the ratio between villus height and crypt depth were calculated (21). For each tissue sample of the cecum and colon, 20 crypts were examined at $\times 100$ magnification for crypt depth. To assess the extent of cell proliferation of the intestinal epithelium, immunohistochemical staining with mouse anti-proliferating cell nuclear antigen (anti-PCNA) as described in detail by Bilič-Šobot et al. (21) on all samples using the Dako REAL ${ }^{\mathrm{TM}}$ EnVision detection system (Dako, Glostrup, Denmark) was performed. In the small intestine segments, the number of PCNA-positive enterocytes was counted at the level of the villus-crypt boundary, which encompasses the upper crypt/lower villus region at a length of $150 \mu \mathrm{m}$ (10 villus-crypt units per animal) at $\times 40$ objective magnification. In the colon segments, the number of PCNA-positive enterocytes was counted in 10 well-oriented crypts per animal at $\times 20$ objective magnification.

\section{Calculations}

DM feed intake and apparent digestibility coefficients of organic matter (OM), crude protein (CP), GE, ether extract, crude fiber, $\mathrm{NDF}$, and ADF were calculated from the values obtained in Exp. 1 using the total collection method. The NE content of the diet was calculated for HNE and LNE according to Noblet et al. (8) (using the average of the values obtained by equations 3,4 , and 5 , with digestible energy (DE) as predictor), and the NE content of the MNE diet was assumed to be the average of values calculated for HNE and LNE diets. In Exp. 2, average daily gain (ADG) and gain to feed ratio (G:F) were calculated for each of 4-week experimental periods: day 84 to 114 , day 115 to 142 , and day 143 to 170 . Additionally, DE, metabolizable energy (ME), and NE intake were calculated from DM feed intake and corresponding energy concentration of experimental diets as estimated in Exp. 1 and used in the calculation of body weight (BW) gain to NE intake ratio (G:NE). The energy values of experimental diets, average DFI (ADFI), and G:F were calculated on 100\% DM and subsequently adjusted to $89 \%$ DM content. Dressing percentage was calculated as the ratio between HCW and final BW, measured $24 \mathrm{~h}$ before slaughter without prior fasting. Gonadosomatic index (\%) was calculated as testicular weight (weight of right and left testes including epididymis) divided by final BW.

\section{Statistical Analysis}

ANOVA was performed using the mixed model procedure of SAS (PROC MIXED, SAS Inst., Cary NC, USA). Repeated measurements of digestibility and nitrogen balance data $(n=8)$ in Exp. 1 were evaluated by including the fixed effects of diet group and stage and their interaction and the random effect of pig (included in the repeated statement). In Exp. 2, the effect of the diet (NE concentration) on growth performance was evaluated considering the fixed effects of dietary treatment and litter for the phases before (day 84 to 114) and after immunization (day 115 to 170). For the phase after the effective immunization, two 4week periods were looked at separately, and the model included dietary group, period, their interaction, and litter, with a pig as a repeated variable. Because the effect of immunocastration on growth performance is now well established and was not the focus of the present study, comparisons of phases before and after immunization periods are not presented.

To predict the voluntary energy intake, data from the DM feed intake measurements per week, energy (ME and NE) content of the diets, and BW from the age of 84 days onwards were used to calculate relationships between cumulative energy intakes (y; ME or NE) and BW according to the following model:

If age $<112$ days:

$y=a_{\text {diet before } V 2} \times B W^{c_{\text {diet }}}+b_{\text {pig }}$

If age $\geq 112$ days:

$y=a_{\text {diet after } V 2} \times B W^{c_{\text {diet }}}+\left(a_{\text {diet before } V 2}-a_{\text {diet after } V 2}\right) \times$

$B W_{\text {age }}=112+b_{\text {pig }}$

$\mathrm{a}_{\text {diet }}$ beforeV2 and $\mathrm{a}_{\text {dietafterV2 }}$ are the slopes of the relationship for each diet, before and after immunization (V2), respectively; $\mathrm{c}_{\text {diet }}$ is the exponent applied to BW for each diet; $\mathrm{BW}_{\text {age }}=112$ is the BW at 112 days of age; and $b_{\text {pig }}$ is the intercept of the relationship for each pig (so that cumulative intake of experimental diets equals zero at the start of the experiment, i.e., at 84 days of age). The parameters of the model were evaluated on the cumulative intakes using the NLIN procedure of SAS (PROC NLIN, SAS Inst., Cary NC, USA) to avoid threshold effects caused by the way feed intake was measured (continuous access to the feeder without restriction during the few hours preceding measurement). The hypothesis for a single $\mathrm{c}_{\text {diet }}$ exponent applied to BW for all diets was tested for ME and NE intake using the extra sum of squares reduction test (22). As this test was never significant $(p>0.10)$, a single exponent (1.43) was considered for further statistical analyses to test the effect of diet and period (P1 = before and $\mathrm{P} 2=$ after V2) on the regression coefficients (slopes) of the relationship.

Carcass trait, boar taint compounds, and testicular weight in Exp. 2 were analyzed using a fixed-effects model of diet, treatment group, litter within slaughter batch, and slaughter batch.

Measurements of morphology and mitosis cell count of small and large intestinal segments in Exp. 2 were evaluated by including the fixed effects of a dietary group within the intestinal part and the random effect of the pig.

The individual pig was considered as the experimental unit for all data analyses. The least-squares means were compared using Tukey's test with statistical significance based on $p<0.05$.

\section{RESULTS}

The chemically determined values for the dietary CP, crude fiber, ether extract, and starch concentrations in the representative samples of the LNE, MNE, and HNE diets (Table 1) were as expected. No particular problems occurred in Exp. 1. In Exp. 2, one pig died during the experiment (the HNE group), two were excluded due to umbilical hernia (1 in the LNE group and 1 in the MNE group), and one was excluded due to broken forelimb (the MNE group), providing 41 pigs weighing on average $122.5 \mathrm{~kg}$ at the end of Exp. 2

(Table 2).

The effectiveness of immunocastration in the growth trial (Exp. 2) was assessed considering backfat concentrations of 
TABLE 2 | Effect of dietary net energy concentration on feed intake and growth performance in immunocastrated pigs.

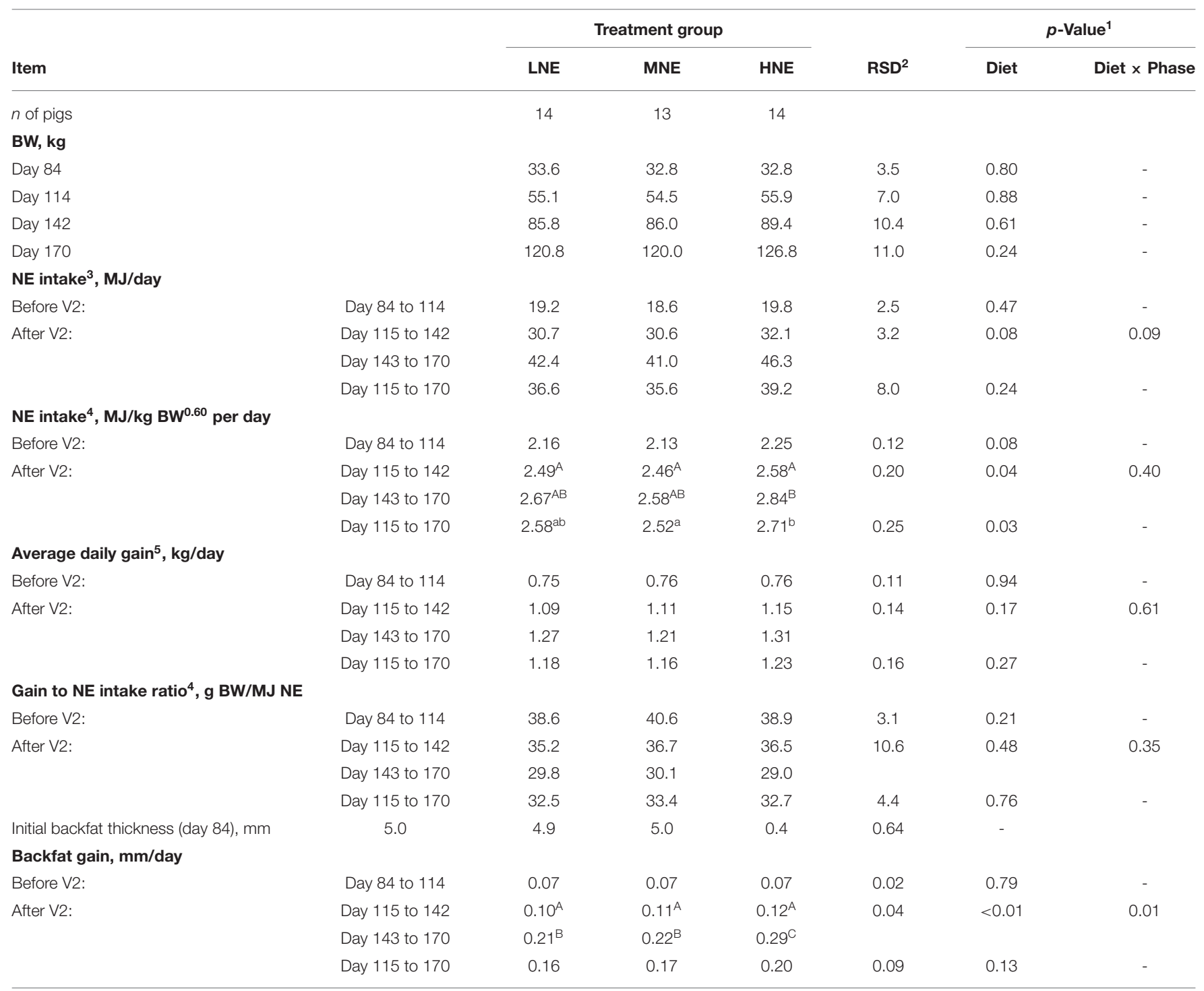

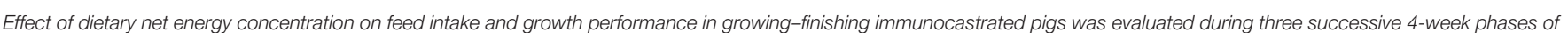

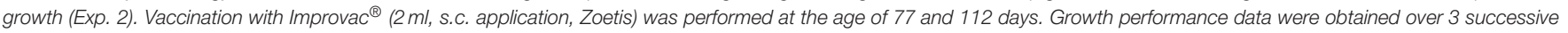

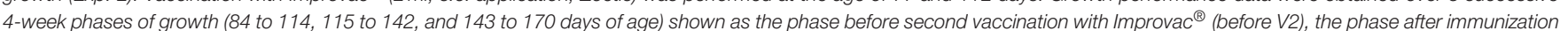

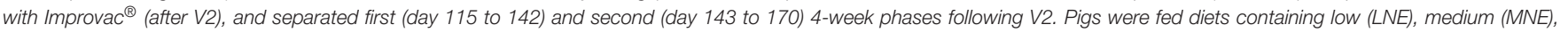

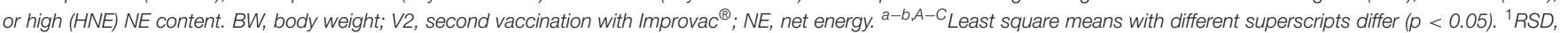

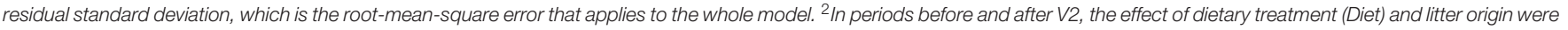

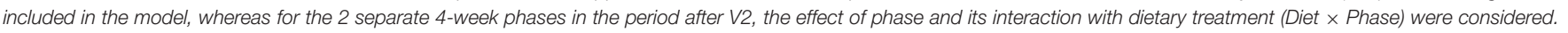

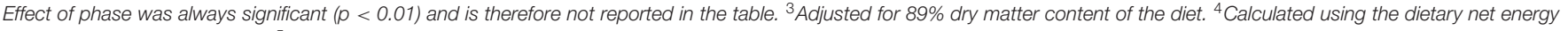

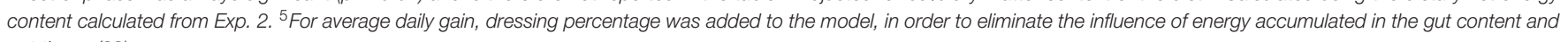
gut tissue (23).

androstenone and skatole and testicular weight at slaughter. With the use of these parameters, no non-responders to immunocastration were identified. Androstenone and skatole concentrations averaged $0.27 \pm 0.08$ and $0.05 \pm 0.03 \mu \mathrm{g} / \mathrm{g}$ of liquid fat, which is just above the detection limit of the determination method. Weight of testes with epididymis averaged $247 \pm 147 \mathrm{~g}$ ( $p=0.78$; results not shown), and the gonadosomatic index averaged $0.204 \pm 0.132(p=0.78$; results not shown).

\section{Nutrient Digestibility of Experimental Diets (Experiment 1)}

The results of the digestibility trial (Exp. 1) presented in Table 3 reveal a lower $(p<0.05)$ digestibility of OM, CP, ether extract, and energy in the LNE diet, in accordance with its greater fiber content. On the other hand, greater crude fiber digestibility was noted for the LNE diet $(p<0.01)$, whereas NDF and ADF digestibility were not affected ( $p=0.83$ and 0.12 ) by diet composition. Similarly, nitrogen intake and retention were 
TABLE 3 | Digestive utilization of nutrients, nitrogen balance, and energy values of diets (Exp. $\left.1^{\mathrm{a}}\right)$.

\begin{tabular}{|c|c|c|c|c|}
\hline \multirow[b]{2}{*}{ Item } & \multicolumn{2}{|c|}{$\operatorname{Diet}^{b}$} & \multirow[b]{2}{*}{$\mathrm{RSD}^{c}$} & \multirow[b]{2}{*}{$p$-Value ${ }^{d}$} \\
\hline & LNE & HNE & & \\
\hline BW at first stage (kg) & 47.1 & 44.7 & 6.4 & 0.71 \\
\hline ADFI during first stage ${ }^{e}$ (kg of feed) & 2.28 & 1.94 & 0.29 & 0.29 \\
\hline BW at second stage $(\mathrm{kg})$ & 67.7 & 70.5 & 7.2 & 0.70 \\
\hline ADFI during second stage ${ }^{e}(\mathrm{~kg}$ of feed) & 2.73 & 2.62 & 0.34 & 0.75 \\
\hline \multicolumn{5}{|l|}{ Digestibility coefficients (\%) } \\
\hline Organic matter & 81.6 & 87.2 & 1.0 & 0.02 \\
\hline Crude protein & 73.2 & 82.2 & 2.1 & 0.02 \\
\hline Ether extract & 58.3 & 69.1 & 2.5 & 0.02 \\
\hline Crude fiber & 44.7 & 29.7 & 3.7 & 0.02 \\
\hline Neutral detergent fiber & 52.1 & 52.8 & 4.2 & 0.83 \\
\hline Acid detergent fiber & 45.0 & 38.9 & 3.6 & 0.12 \\
\hline Energy & 78.9 & 85.1 & 1.2 & 0.02 \\
\hline \multicolumn{5}{|l|}{ Energy values $^{e}$ (MJ/kg of feed) } \\
\hline $\mathrm{DE}$ & 12.70 & 13.87 & 0.20 & 0.01 \\
\hline $\mathrm{ME}^{f}$ & 12.31 & 13.42 & 0.25 & 0.02 \\
\hline $\mathrm{NE}^{g}$ & 9.29 & 10.38 & 0.15 & $<0.01$ \\
\hline \multicolumn{5}{|l|}{ N balance (g/day) } \\
\hline Intake & 60.6 & 58.4 & 1.7 & 0.18 \\
\hline \multicolumn{5}{|l|}{ Excretion } \\
\hline In feces & 16.2 & 10.3 & 0.8 & $<0.01$ \\
\hline In urine & 13.6 & 20.5 & 2.2 & 0.04 \\
\hline Retained & 30.7 & 27.6 & 3.9 & 0.34 \\
\hline $\mathrm{N}$ retention (\% of digested $\mathrm{N}$ ) & 69.4 & 59.2 & 6.5 & 0.14 \\
\hline
\end{tabular}

BW, body weight; ADFI, average daily feed intake; DE, digestible energy; $M E$, metabolizable energy; NE, net energy; $N$, nitrogen. ${ }^{a}$ Exp. 1 consisted of a digestibility trial and nitrogen balance study, and it was performed using 4 pigs (immunocastrated with Improvac ${ }^{\circledR}$ at age of 77 and 105 days) fed the 2 extreme experimental diets of Exp. 1 during 2 successive periods (first prior and second after immunization with Improvac ${ }^{\circledR}$ ). Each period consisted of one adaptation sub-period (14 days) and a subsequent collection sub-period (7 days) so that 2 pigs were fed each diet at each stage. ${ }^{b}$ Diets with low (LNE) or high (HNE) NE content. ${ }^{c} R S D$, residual standard deviation. ${ }^{d}$ Values were tested for the effect of diet; results are least-squares means; the measurement was considered repeated per period. ${ }^{e}$ Adjusted for $89 \%$ DM content. ${ }^{f}$ It should be noted that ME did not account for the loss of energy as $\mathrm{CH}_{4} .{ }^{9} \mathrm{Calculated}$ according to Noblet et al. (8); average of equations 3,4 , and 5.

similar for the LNE and HNE dietary treatments $(p=0.18$ and 0.34$)$, whereas greater nitrogen fecal losses $(p<0.01)$ and lower nitrogen urinary losses $(p=0.04)$ were observed for the LNE treatment group. Consistent with the objective of the study, the experimental diets differed in their energy contents; DE $(p=0.01), \mathrm{ME}$ (without the contribution of $\mathrm{CH}_{4} ; p=0.02$ ), and calculated NE $(p<0.01)$ contents of HNE and LNE diets were 13.9 vs. $12.7,13.4$ vs. 12.3 , and 10.4 vs. $9.3 \mathrm{MJ} / \mathrm{kg}$, respectively (Table 3).

\section{Feed Intake and Performance (Experiment 2)}

No effect of the diet (Table 2) on BW at any stage of the experiment was detected. The period after effective immunization significantly affected NE feed intake and growth performance ( $p<0.01$; Table 2), whereas the phase and dietary treatment interaction after immunization was significant only for backfat gain $(p<0.01$; Table 2). Diet composition did not affect the ADFI in any period of the experiment $(p>0.05$; data not shown), and NE intake was affected by the changes in diet NE concentration, but this effect was significant only in P2. To be more precise, greater daily NE intake expressed as megajoules per kilogram of $\mathrm{BW}^{0.60}$ was noted between the HNE dietary group compared with the MNE dietary group in P2 $(p=0.03$; Table 2). There was no effect (Table 2) of dietary NE concentration on ADG and G:NE in any period of the experiment. A difference in backfat gain was observed in the second phase after immunization (day 143 to 170), where greater $(p<0.01$; Table 2$)$ backfat gain was noted for the HNE group compared with the MNE and LNE groups, which was also reflected as a tendency ( $p=0.13$; Table 2$)$ toward greater backfat gain in P2 (day 115 to 170 ) in the HNE group.

To further elucidate the effect of energy intake and period after $\mathrm{V} 2$, a detailed analysis of the energy intake data was performed, based on the cumulative consumption of the experimental diets shown in Figure 2. The slopes of the relationships between cumulative energy intake and BW were tested for the effects of phase (prior $=\mathrm{P} 1$ or after immunization $=\mathrm{P} 2$ ) and diet using the 1.43 exponent applied to BW. Regardless of diet, the change in cumulative energy intake per kg BW gain never differed between periods for cumulative ME and NE intake (Table 4). In each period (before and after V2), the change in cumulative ME intake per $\mathrm{kg} \mathrm{BW}$ gain tended to differ $(p=0.05$ and 0.06$)$ between the two extreme diets, i.e., LNE and HNE, whereas the change in cumulative NE intake per $\mathrm{kg}$ BW increase did not differ between periods and diets and averaged $2.86 \mathrm{MJ} / \mathrm{kg}$ $\mathrm{BW}^{1.43}-463 \mathrm{MJ}$ (Table 4). From the intercept and the slope of the relationship calculated for the first period, it can be estimated that BW at zero cumulative consumption (i.e., at the beginning of the experiment) averaged $34.9 \mathrm{~kg}$ ( $\mathrm{SD}=1.2 \mathrm{~kg}$ ); the latter is close to the values reported in Table 2 at 84 days of age.

\section{Morphology, Mitotic Cell Count, and Skatole and Indole Production in Intestinal Segments (Experiment 2)}

The effect of a reduction in NE concentration of the diet on the intestinal histo-morphological features $(p<0.01$; Table 5) was evident in the jejunum, ileum, ascending, and descending colon, whereas the mucosa of the duodenum and cecum was not affected (Table 5). To be more specific, greater villus surface area, villus width, villus height, villus perimeter, crypt depth, and thickness of the intestinal mucosa were noted for pigs fed LNE diet $(p<0.01$; Table 5) than those fed HNE diet, with those fed MNE diet being intermediate. In the ileum, crypt depth increased with dietary NE content reduction ( $p<0.01$; Table 5), whereas the thickness of the intestinal mucosa was increased in the LNE and MNE dietary groups compared with the HNE group ( $p<0.01$; Table 5). Despite the change in histo-morphological characteristics of the intestinal mucosa, dietary treatment did not appear to be 


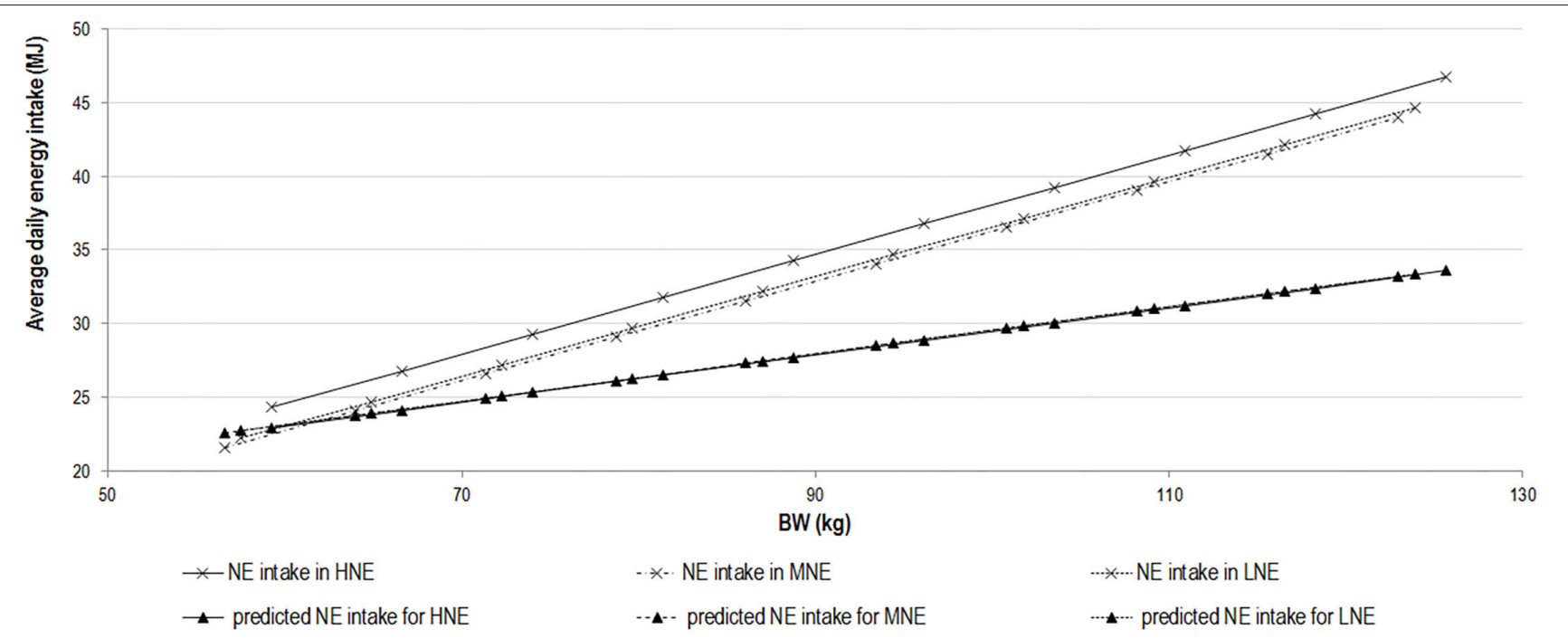

FIGURE 2 | Relationship between daily net energy intake and body weight of growing-finishing immunocastrated pigs. Relationship between daily net energy (NE) intake and body weight of growing-finishing immunocastrated pigs (vaccinated with Improvac ${ }^{\circledR}$, Zoetis at the age of 77 and 112 days) on experimental diets containing 10.4 (LNE) and 11.0 (MNE) MJ/kg of DM in comparison with the standard diet containing 11.6 (HNE) MJ/kg of fed diets. Predicted NE intake was calculated as $4.09 \times$ BW $^{0.43}$. LNE, low NE; MNE, medium NE; DM, dry matter; BW, body weight.

TABLE 4 | Relationship between cumulative dietary energy intake and body weight in immunocastrated pigs.

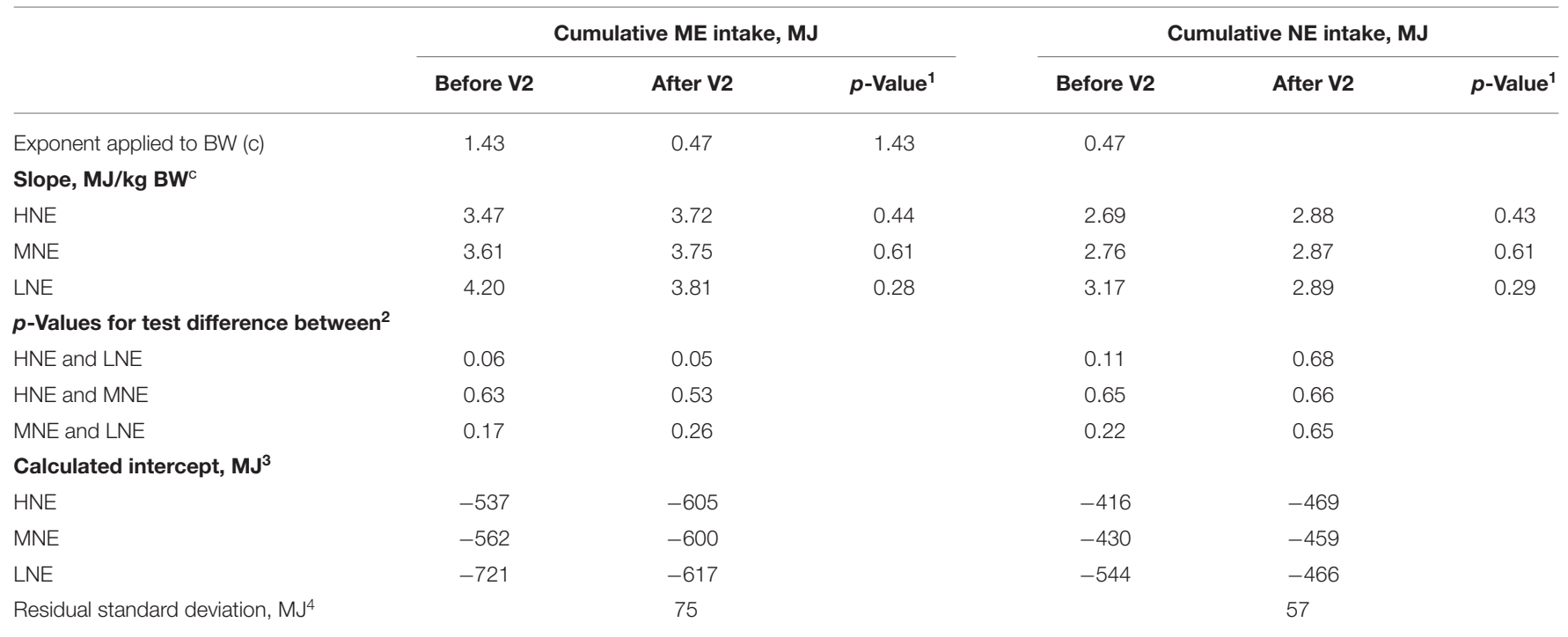

Relationship between cumulative dietary energy intake (in MJ) before and after effective immunocastration (V2) and BW in growing-finishing immunocastrated pigs ( $n=41$ ) according to diet energy content. Vaccination with Improvac ${ }^{\circledR}(2 \mathrm{ml}$, s.c. application, Zoetis) was performed at the age of 77 (V1) and 112 (V2) days. Parameters are estimated for the generalized relationship between cumulative GE/DE/ME/NE intake $(\mathrm{MJ})$ and body weight $(\mathrm{kg})$ before and after second vaccination for immunocastration and different diets (HNE, high NE diet; MNE, medium NE diet; and LNE, low NE diet) in the form:

If age < 112:

$y=a_{\text {diet before }} 22 \times B W^{c}$ diet $+b_{\text {pig }}$

If age $\geq 112$ :

$y=a_{\text {diet after } V_{2} \times B W^{c} \text { diet }}+\left(a_{\text {diet before } V_{2}}-a_{\text {diet after }} V_{2}\right) \times B W_{\text {age }}=112+b_{\text {pig }}$

$a_{\text {diet before } V 2}$ and $a_{\text {diet after }} V_{2}$ are the slopes of the relationship for each diet, before and after V2, respectively; $C_{\text {diet }}$ is the exponent applied to BW for each diet, BWage $=112$ is the $B W$ at 112 days of age; and $b_{\text {pig }}$ is the intercept of the relationship for each pig. BW, body weight; ME, metabolizable energy; NE, net energy; GE, gross energy; DE, digestible energy. ${ }^{1} p$-Values of the residual sum of squares of the reduced model (single exponent $c$ for all diets, or single exponent $c$ for all diets plus single slope for both periods - prior and after V2 for each diet) are equal to those of the full model. Hypothesis for which $p>0.05$ is indicative that the reduced model is adequate to describe the data. ${ }^{2} p$-Values of the residual sum of squares of the reduced model (single exponent c for all diets plus single slope for 2 diets at each period - prior and after V2) are equal to those of the full model. Hypothesis for which $p>0.05$ is indicative that the reduced model is adequate to describe the data. ${ }^{3}$ Intercept calculated as the average per diet of individual $b_{\text {pig }}$ values for P1 (prior V2) and as the average per diet of individual [( $a_{\text {diet before } 22}-a_{\text {diet after }}$ 2) $\times B W_{\text {age }}=112+b_{\text {pig] }}$ for P2 (after V2). ${ }^{4}$ Residual standard deviation for the full model calculated as the square root of residual sum of squares divided by residual degrees of freedom.

${ }^{c}$ Exponent applied to BW. 
TABLE 5 | Effect of changes in dietary net energy concentration on intestinal morphology and mitotic cell count.

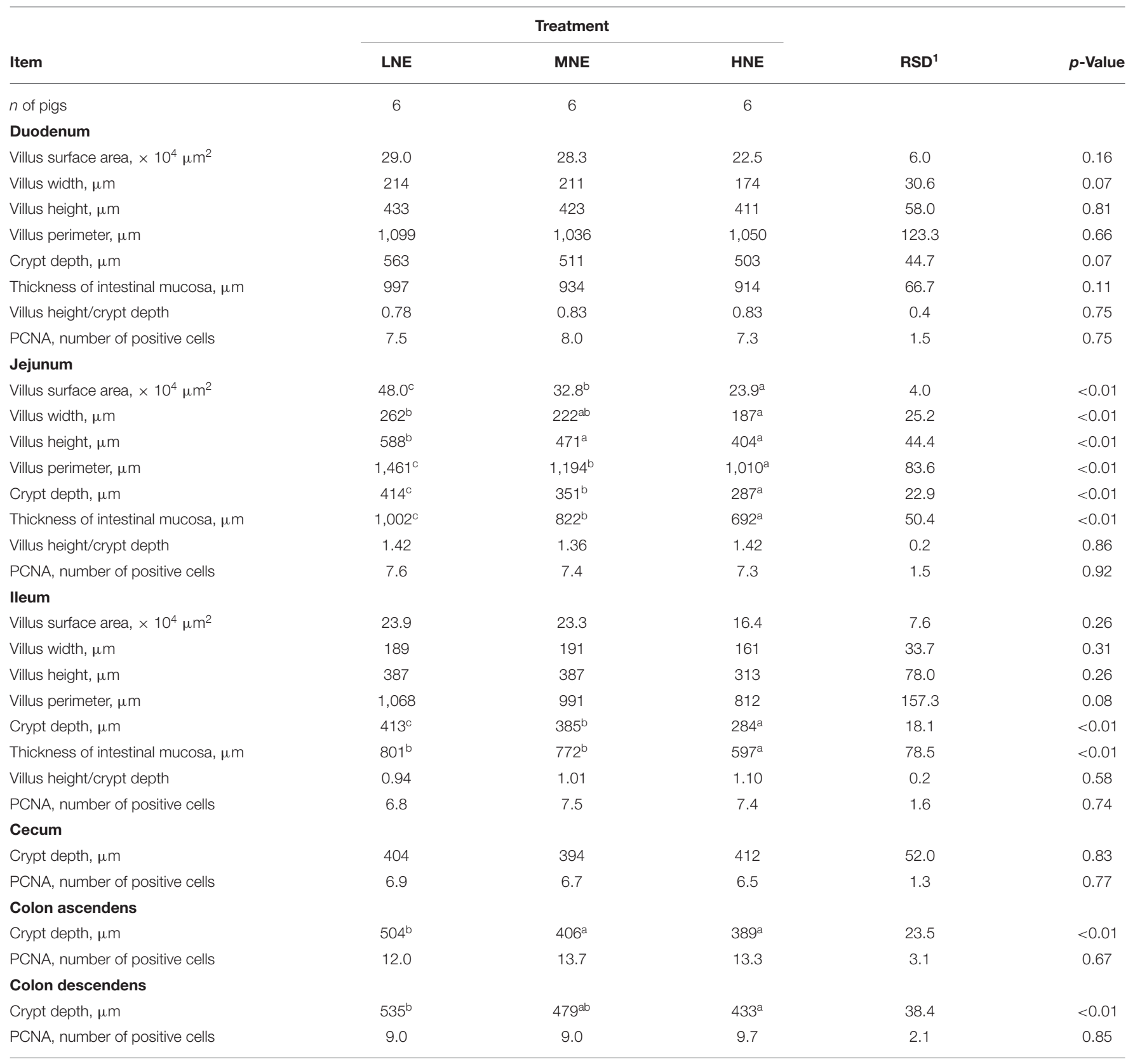

Effect of changes in dietary net energy concentration on intestinal morphology and mitotic cell count was evaluated in growing-finishing immunocastrated pigs, fed diets containing Iow (LNE), medium (MNE), or high (HNE) NE content. Vaccination with Improvac ${ }^{\circledR}(2 \mathrm{ml}$, s.c. application, Zoetis) was performed at age of 77 and 112 days. NE, net energy; PCNA, proliferating cell nuclear antigen. ${ }^{a-c}$ Least squares means within a row with different superscripts differ $(p<0.05) .{ }^{1} R S D$, residual standard deviation, which is the root-mean-square error that applies to the whole model.

associated with the enterocyte proliferation (i.e., PCNA-positive cell number) in any of the intestinal sections studied $(p>0.05$; Table 5).

Indole concentration in the ascending colon was decreased $(p<0.01$; Table 6) by decreasing dietary NE concentration, while skatole concentration in the cecum was increased with $\mathrm{NE}$ reduction $(p<0.01$; Table 6$)$ and tended to decrease with NE reduction in the descending colon ( $p=0.07$; Table 6).

\section{Carcass Characteristics and Fat Deposition (Experiment 2)}

In agreement with the lack of effect of diet on BW, no effect ( $p=0.20)$ was observed on HCW or weight of major carcass parts (data not shown). However, it should be noted that the numerical variation in dressing percentage between dietary treatment groups, although not significant $(p=0.11)$, was quite high ( $1.5 \%$ and $0.9 \%$ points lower for the LNE and MNE groups, 
TABLE 6 | Effect of changes in dietary net energy concentration on intestinal skatole and indole production.

\begin{tabular}{|c|c|c|c|c|c|}
\hline \multirow[b]{2}{*}{ Item } & \multicolumn{3}{|c|}{ Treatment } & \multirow[b]{2}{*}{$\mathrm{RSD}^{1}$} & \multirow[b]{2}{*}{$p$-Value } \\
\hline & LNE & MNE & HNE & & \\
\hline$n$ of pigs & 14 & 13 & 14 & & \\
\hline \multicolumn{6}{|c|}{ Indole in intestinal content, $\mu \mathrm{g} / \mathrm{g}$} \\
\hline Cecum & 8.13 & 14.0 & 17.7 & 7.2 & 0.10 \\
\hline Colon ascendens & $3.9^{a}$ & $10.8^{b}$ & $19.7^{b}$ & 5.5 & $<0.01$ \\
\hline Colon descendens & 14.0 & 6.6 & 9.9 & 6.8 & 0.20 \\
\hline \multicolumn{6}{|c|}{ Skatole in intestinal content, $\mu \mathrm{g} / \mathrm{g}$} \\
\hline Cecum & $21.9^{b}$ & $5.5^{\mathrm{a}}$ & $4.3^{\mathrm{a}}$ & 5.8 & $<0.01$ \\
\hline Colon ascendens & 15.4 & 16.5 & 22.9 & 21.5 & 0.35 \\
\hline Colon descendens & 5.5 & 9.7 & 17.9 & 8.2 & 0.07 \\
\hline
\end{tabular}

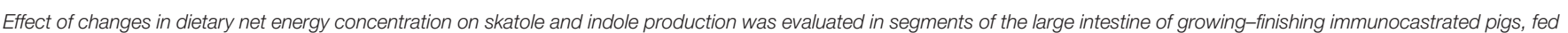
diets containing low (LNE), medium (MNE), or high (HNE) net energy content. Vaccination with Improvac ${ }^{\circledR}$ (2 ml, s.c. application, Zoetis) was performed at age of 77 and 112 days.

${ }^{a-b}$ Least squares means within a row with different superscripts differ $(p<0.05) .{ }^{1} R S D$, residual standard deviation, which is the root-mean-square error that applies to the whole model.

TABLE 7 | Effect of changes in dietary net energy concentration on carcass and meat quality traits.

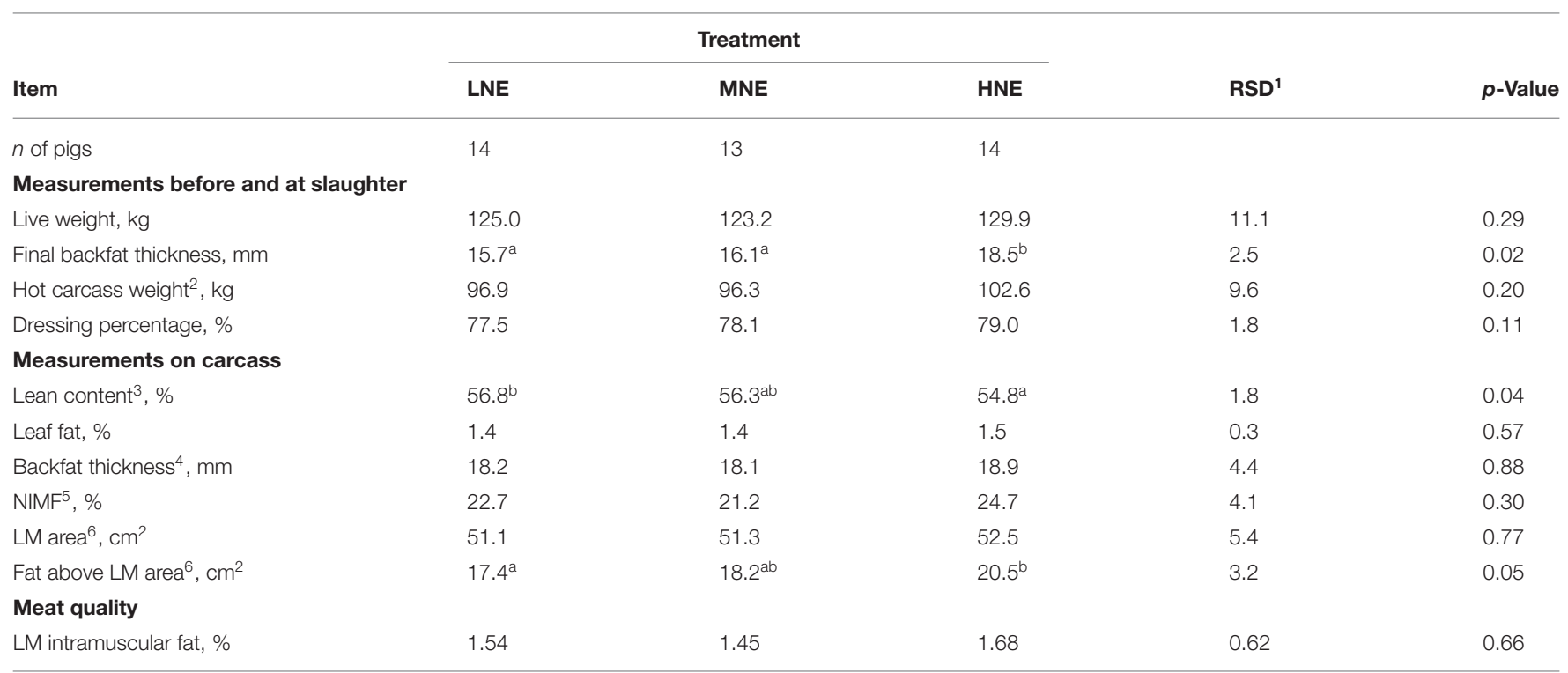

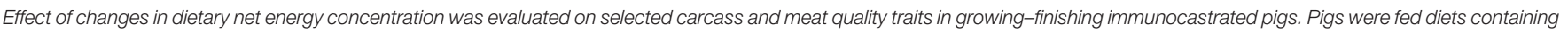

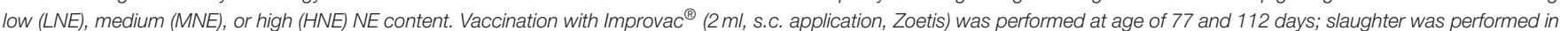

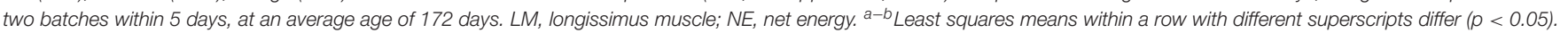

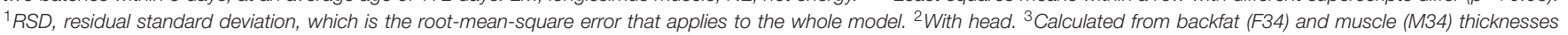

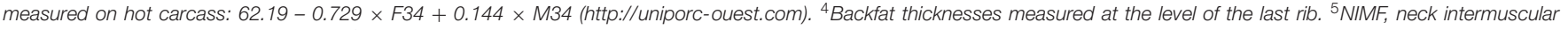
fatness, assessed by image analysis (5). ${ }^{6} \mathrm{LM}$ area and fat over $L M$ area were assessed by image analysis (5).

respectively, compared with the HNE group; Table 7), consistent with the effect of dietary treatment on backfat gain measured in vivo by ultrasound ( $p=0.02$; Table 7 ) and as the area of fat covering the longissimus muscle ( $p=0.05$; Table 7) was lower in LNE and MNE pigs than in pigs fed HNE diet. Decreased subcutaneous fatness was reflected in greater lean meat content ( $p=0.04$; Table 7$)$ of LNE compared with HNE pigs.

\section{DISCUSSION}

In IM pigs, rapid changes in hormonal status 10 to 15 days after immunization (2) result in increased voluntary feed intake, greater $\operatorname{ADG}(3,24)$, and altered energy metabolism associated with increased lipid deposition $(25,26)$. Consequently, this leads to greater BFT and lower lean carcass content [as determined by the meta-analytical studies $(3,4)]$, in parallel with the effective elimination of boar taint compounds in adipose tissue. However, most of the studies conducted to date dealt with pigs slaughtered 4 to 6 weeks after immunization, whereas little is known about what happens when the delay between immunization and slaughter is further extended. In the present study, this delay was increased up to 8 weeks without any adverse effects on meat boar taint: taking into account androstenone and skatole levels in the backfat together with the testicular weight, all pigs 
could be considered fully immunized. Similarly, Kubale et al. (27) observed no evidence of functional or morphological recovery of testicular function within 8 weeks after immunization.

The high energy digestibility observed in Exp. 1 with a low fiber (i.e., high starch) diet is to be expected and agrees with previous studies (28-30). It also confirms that fiber-rich feedstuffs can be successfully used as an energy diluting factor in growing-finishing diets because of components with a low digestive utilization (31). The inclusion of dietary fiber also increases the endogenous losses, resulting in a perceived decrease in the digestion of energy and nutrients in monogastric animals (32). Indeed, by increasing NDF content (plus 41 and $81 \mathrm{~g} / \mathrm{kg} \mathrm{DM}$ in MNE and LNE diets, respectively), the calculated NE content of the diets in the present study was reduced by approximately 5 and 10\% in MNE and LNE diets. On the other hand, in Exp. 1, dietary fiber intake resulted in increased digestibility of fiber components. This may be explained by the ability of the intestinal mucosa to adjust to a high-fiber diet with a gradual change in microbial fermentation as also confirmed in Exp. 2 by the results of skatole and indole production Additionally, dietary fiber fermentation by the intestinal microbiota results in short-chain fatty acid (SCFA) production (33), which can directly contribute to the nutritional value of meal as an energy source (34), but with a lower energetic efficiency than starch and lipid (35). As indicated by Jin et al. (36), the inclusion of $10 \%$ high-fiber source in diets of growing pigs for 14 days caused an increased width of villi and depth of the crypts in the jejunum and ileum. The same study also showed that high dietary fiber intake increased the rate of cell proliferation and crypt depth in the colon. However, this was not evident in the present study at the level of the small intestine, despite the changes in histomorphological features, which may be since intense changes in intestinal morphology may have occurred earlier (immediately after the change in diet, e.g., at the age of 84 days).

In the present study, skatole level increased with the $\mathrm{NE}$ reduction in the cecum but tended to decrease with NE reduction in the descending colon. The reason for the differential response in different intestine segments may be related to the progressive decrease in the flow of digesta toward the distal colon that changes the fermentation metabolite and bacterial profile (37, 38). Nevertheless, an overall reduction of skatole with decreased $\mathrm{NE}$ and increased amount of dietary fiber can be observed. Similarly, Li et al. (39) demonstrated that the addition of sugar beet pulp, one of the ingredients used in the present study to reduce the energy level of the experimental diet, had a significant inhibitory effect on skatole formation in the intestine. The reasons may be several, from increased intestinal passage rate (37) and increased fecal water content diluting and lowering skatole accumulation rate to serving as a fermentable energy source, preventing amino acid (i.e., tryptophan) fermentation and skatole production (40). In the absence of fermentable carbohydrates as an energy source, microbial fermentation shifts to amino acids and uses the carbon skeleton of amino acids as an energy source (41), which also leads to increased production of intestinal skatole (42) as an amino acid (tryptophan) metabolite. On the other hand, in the presence of energy from fermentable carbohydrates, the resident microbes in the colon retain more amino acids for their growth (43). Along with decreasing skatole, indole production behaved oppositely (decreased with $\mathrm{NE}$ reduction in the ascending colon). Although skatole and indole production could be positively correlated due to their common precursor (42), the synthesis of both compounds is $\mathrm{pH}$-dependent [indole-forming bacteria favor basic and skatoleproducing bacteria acidic conditions (44)] and can be influenced in different ways by dietary components (45).

Pigs are generally able to adapt voluntary feed intake to dietary characteristics, and energy density is usually the first determinant of ADFI as long as the maximum capacity of the digestive tract is not reached $(23,46)$. However, the results of the present study are evidence of more complex interactions due to the inclusion of dietary fiber in the diet, which can be continually fermented by intestinal microbiota, providing a stable energy source and thus prolonged satiety (47), and changes in lipid metabolism (enhanced lipid deposition and lipogenic activity) after immunocastration $(25,48)$. In agreement with the results of Zeng et al. (49), reduction of diet NE concentration did not significantly affect the ADFI of IM pigs after immunization, which might indicate that the pigs have already reached their maximal feed intake capacity or that the dietary source used in the lowest NE diets had a marked effect on pig satiety $(23,50)$. The latter might be due to increased intestinal volume as a consequence of greater bulk density and water-holding capacity of a high-fiber diet (51) and, additionally, due to the effect of SCFA on appetite regulation and long-term satiety (52). Since the ADFI of IM pigs in the first weeks after immunization is greater than in their surgically castrated counterparts [by $\sim 100$ g/day; $(1,3,24)]$, the physical limits for ADFI may be reached independently of the diet energy content. In the present study, a tendency toward lower NE intake was noted for LNE and MNE diet in the second 4-week period after immunization. However, only pigs consuming the MNE diet, expressed on a metabolic BW basis (MJ $/ \mathrm{kg} \mathrm{BW}^{0.60}$ per day), reached significantly lower $\mathrm{NE}$ intake after immunization. This might indicate a nonlinear effect of reducing diet energy density on the regulation of energy intake or that LNE pigs still compensated for the lower NE dietary content with greater ADFI (which was numerically, but not statistically greater), whereas this was not the case for MNE pigs. It was not possible to measure feeding behavior in our trial, but our results on DFI and the influence of dietary fiber on fermentation and satiety suggest that modifications on feeding behavior should be considered to explain the difference between treatments. Additionally, the variability of $\mathrm{NE}$ intake $(\mathrm{MJ} / \mathrm{kg}$ $\mathrm{BW}^{0.60}$ per day) is much smaller, implying that the variability of daily NE intake and ADFI is partly explained by the variability in BW, which was numerically lower for the LNE and MNE groups. However, when cumulative energy intake is considered as a function of BW, small differences in the slopes for cumulative DE and ME intake can be observed (Table 4) whereas no difference was observed in the slope of the relationship between cumulative $\mathrm{NE}$ intake and BW between periods and diets. It can thus be considered that maximal daily NE intake (MJ), which does not depend on diet characteristics, was achieved regardless of the dietary energy content and can be described as the first derivative according to $\mathrm{BW}$ of the average prediction equation 
for cumulative NE intake. It corresponds to $4.09 \mathrm{MJ} / \mathrm{kg} \times \mathrm{BW}^{0.43}$ MJ when BW varied from 40 to $125 \mathrm{~kg}$.

To eliminate the influence of differential gut content and visceral tissue related to the ADFI differences (23), the ADG was adjusted for dressing percentage, and it remained unaffected by $5 \%$ or $10 \%$ reduction of the diet NE concentration in the present study. When even stricter quantitative feed restriction was applied in IM pigs, a decrease in ADG was reported (by 20 and $12 \%$ at 78 and $85 \%$ of ad libitum feed intake, which corresponds to -6.9 and $-4.6 \mathrm{MJ}$ consumed NE per day, respectively), with no improvement in G:F (7). Due to energy dilution in the present study, growth efficiency was evaluated on NE basis as G:NE, to express energy requirements and dietary energy values on the same scale (53). In accordance with the results of Quiniou and Noblet (7) in barrows, G:NE was similar in all 3 dietary groups, indicating that changes in diet NE concentration did not influence the growth rate of IM pigs, although the partitioning of energy was different among dietary groups. Namely, in accordance with the objective of the study, changes in diet $\mathrm{NE}$ concentration (10\% compared with the standard 10.4 MJ NE/kg feed) resulted in a reduced backfat deposition. The difference between the 3 dietary treatments in the rate of backfat gain was significant during the second 4week period following immunization, resulting in a $28 \%$ lower rate of backfat deposition. In general, lipid deposition in pigs increases gradually with BW (54), but IM pigs are characterized by an intense increase in lipid deposition after immunization and a subsequent increase in the ratio between lipid and protein deposition [LD:PD; (26)]. It was therefore expected, and demonstrated in the present study, that the difference in backfat gain due to the reduced dietary NE content would become noticeable only after a long period after immunization, providing an additional argument that the pigs were not able to fully adjust their feed intake to achieve a constant energy intake across treatments.

The results of carcass traits confirm the results observed for performance. In agreement with a similar study in barrows (7), the carcass weight of IM pigs in the present study was not affected by the reduction in diet NE concentration, whereas lean content was improved. Weights of prime cuts were similar in all 3 dietary treatment groups, whereas the response of fat depots varied. The subcutaneous fat depot was significantly reduced with reduction of the NE content of the feed, whereas smaller (numerical only) reduction was observed for leaf fat and intramuscular fat. Intramuscular fat content was below the level of $2 \%$ to $3 \%$ required to impact flavor and juiciness to pork meat (55) in all dietary groups, most likely due to the genetic lines used. Additionally, the lack of effect of NE reduction on leaf fat deposition is expected given the relative growth rate of different fat depots, which serve as a source of energy. As demonstrated in barrows, leaf fat, located within the abdominal cavity, exhibits the most rapid response to prolonged dietary stimuli, followed by subcutaneous and intermuscular (and intramuscular) fat deposition (56-58). In the present study, pigs were fed on an ad libitum basis, which means that they were not in energy deficiency, because pigs can adapt feed intake to the energy density of the feed $(23,46)$. We can then assume that eventual additional energy to the one required for basal metabolic needs consumed by pigs on the LNE diet was firstly deposited to leaf fat and less was available for other tissues. Regarding the effect of quantitative feed restriction in IM pigs, literature reports either no significant effect on carcass leanness and fat deposition $(7,59)$ or only an effect on leaf fat weight (5). The lack of effect of restricted feeding on carcass leanness in the abovementioned studies could be associated with a shorter duration of the restriction. As shown in the present study, backfat deposition significantly increases only after a substantial time post-immunization (4 to 8 weeks after V2).

Taken together, the results of the present experiment confirm that IM pigs are energetically very efficient and suggest that energy dilution in the growing and finishing diet offered ad libitum to IM pigs limits the subcutaneous fat deposition. From a practical perspective, this indicates that in the countries where BFT is a determinant of carcass value (i.e., European Union and the United States), it might be reasonable to use feed restriction (quantitative or qualitative), especially if an extended time between immunization and slaughter is anticipated as well as when pigs are fattened to heavy weights for high-quality drycured products, where excessive adiposity must be avoided due to market demand.

The advantage of immunocastration resides in the long-term boar-like performance of pigs; however, after the immunization, feed intake is considerably increased, which diminishes the advantages in performance. Overall, our results demonstrate that by reducing the NE concentration of the diet by up to $10 \%$ with high-fiber content ingredients, similar energy efficiency (gain to $\mathrm{NE}$ intake ratio) may be achieved due to effective adaptation to the high-fiber diet, as indicated by histo-morphological characteristics of the intestinal mucosa. Moreover, reducing dietary NE concentration lowers intestinal skatole production. This technique provides an advantage in terms of reduced lipid deposition and improved leanness, without affecting growth rate in IM pigs after immunization, which is particularly important when the BFT is a determinant of carcass value and IM pigs are fattened to higher weights (e.g., in heavy pig production) or when a longer delay between immunization and slaughter is practiced.

\section{DATA AVAILABILITY STATEMENT}

The raw data supporting the conclusions of this article will be made available by the authors, without undue reservation.

\section{ETHICS STATEMENT}

The animal study was reviewed and approved by the Ethics Committee of the French Ministry of Agriculture, certificate of authorization for an experiment on live animals No. 35-110 was issued to Etienne Labussière.

\section{AUTHOR CONTRIBUTIONS}

NB-L and EL contributed to the conception, design of the study, and performed the statistical analysis. NB-L, MČ-P, 
MŠ, VK, and EL performed the sample collection and analysis. NB-L wrote the first draft of the manuscript. VK and MČ-P wrote sections of the manuscript. All authors contributed to manuscript revision and read and approved the submitted version.

\section{FUNDING}

The authors acknowledge the financial support of the Slovenian Research Agency (Ph.D. fellowship of NB-L, projects Z7-9416 and L4-5521, programs P4-0133 and P4-0053) and Rennes Metropole and Slovene Human

\section{REFERENCES}

1. Millet S, Gielkens K, de Brabander D, Janssens GPJ. Considerations on the performance of immunocastrated male pigs. Animal. (2011) 5:111923. doi: $10.1017 /$ S1751731111000140

2. Claus R, Lacorn M, Danowski K, Pearce MC, Bauer A. Short-term endocrine and metabolic reactions before and after second immunization against $\mathrm{GnRH}$ in boars. Vaccine. (2007) 25:4689-96. doi: 10.1016/j.vaccine.2007.04.009

3. Batorek N, Candek-Potokar M, Bonneau M, van Milgen J. Meta-analysis of the effect of immunocastration on production performance, reproductive organs and boar taint compounds in pigs. Animal. (2012) 6:13308. doi: $10.1017 /$ S1751731112000146

4. Poulsen Nautrup B, Van Vlaenderen I, Aldaz A, Mah CK. The effect of immunization against gonadotropin-releasing factor on growth performance, carcass characteristics and boar taint relevant to pig producers and the pork packing industry: a meta-analysis. Res Vet Sci. (2018) 119:18295. doi: 10.1016/j.rvsc.2018.06.002

5. Batorek N, Škrlep M, Prunier A, Louveau I, Noblet J, Bonneau M, et al. Effect of feed restriction on hormones, performance, carcass traits, and meat quality in immunocastrated pigs. J Anim Sci. (2012) 90:4593603. doi: $10.2527 /$ jas.2012-5330

6. Lealiifano AK, Pluske JR, Nicholls RR, Dunshea FR, Campbell RG, Hennessy $\mathrm{DP}$, et al. Reducing the length of time between harvest and the secondary gonadotropin-releasing factor immunization improves growth performance and clears boar taint compounds in male finishing pigs. J Anim Sci. (2011) 89:2782-92. doi: 10.2527/jas.2010-3267

7. Quiniou N, Monziols M, Colin F, Goues T, Courboulay V. Effect of feed restriction on the performance and behaviour of pigs immunologically castrated with Improvac ${ }^{\circledR}$. Animal. (2012) 6:1420-6. doi: 10.1017/S1751731112000444

8. Noblet J, Fortune H, Shi XS, Dubois S. Prediction of net energy value of feeds for growing pigs. J Anim Sci. (1994) 72:344-54. doi: 10.2527/1994.722344x

9. Jha R, Berrocoso J F. Dietary fiber and protein fermentation in the intestine of swine and their interactive effects on gut health and on the environment: a review. Anim Feed Sci Technol. (2016) 212:1826. doi: 10.1016/j.anifeedsci.2015.12.002

10. Doran E, Whittington FW, Wood JD, McGivan JD. Cytochrome P450IIEI (CYP2E1) is inducedby skatole and this induction is blocked by androstenone in isolated pig hepatocytes. Chem Biol Interact. (2002) 104:81-2. doi: 10.1016/S0009-2797(02)00015-7

11. Walstra P, Claudi-Magnussen C, Chevillon P, von Seth G, Diestre A, Matthews $\mathrm{KR}$, et al. An international study on the importance of androstenone and skatole for boar taint: levels of androstenone and skatole by country and season. Livest Prod Sci. (1999) 62:15-28. doi: 10.1016/S0301-6226(99)00054-8

12. Škrlep M, Batorek N, Bonneau M, Fazarinc G, Šegula B, Candek-Potokar M. Elevated fat skatole levels in immunocastrated, surgically castrated and entire male pigs with acute dysentery. Vet J. (2012) 194:4179. doi: 10.1016/j.tvjl.2012.04.013

13. Wesoly R, Weiler U. Nutritional influences on skatole formation and skatole metabolism in the pig. Animals. (2012) 2:221-42. doi: 10.3390/ani2020221
Resource Development and scholarship funds for Ph.D. student mobility.

\section{ACKNOWLEDGMENTS}

The authors would like to thank J. Delamarre, Y. Jaguelin, R. Janvier, V. Piedvache, and P. Roger for their assistance in animal care and V. Točaj for her assistance in the analysis of intestinal morphology. Results are part of the Ph.D. thesis of NB-L and were partly presented at the 64th Annual Meeting of the EAAP, Nantes, France, 2013 and Journées de la Recherche Porcine en France, Paris, France, 2014.
14. Bee G, Quiniou N, Maribo H, Zamaratskaia G, Lawlor PG. Strategies to meet nutritional requirements and reduce boar taint in meat from entire male pigs and immunocastrates. Animals. (2020) 10:1950. doi: 10.3390/ani10111950

15. Sauvant D, Perez J-M, Tran G. Tables of Composition And Nutritional Value Of Feed Materials. Wageningen Academic Publishers (2004). p. 304. (accessed October 5, 2021). doi: 10.3920/978-90-8686-668-7

16. van Milgen J, Valancogne A, Dubois S, Dourmad JY, Sève B, Noblet J. InraPorc: a model and decision support tool for the nutrition of growing pigs. Anim Feed Sci Tech. (2008) 143:387-405. doi: 10.1016/j.anifeedsci.2007.05.020

17. AOAC. Official Methods Of Analysis. $15^{\text {th }}$ ed. Arlington, TX: Association of Official Analytical Chemists (1990).

18. Van Soest PJ, Robertson JB, Lewis BA. Methods for dietary fiber, neutral detergent fiber, and nonstarch polysaccharides in relation to animal nutrition. J Dairy Sci. (1991) 74:3583-97. doi: 10.3168/jds.S0022-0302(91)78551-2

19. Denhard M, Bernal-Barragan H, Claus R. Rapid and accurate highperformance liquid chromatographic method for the determination of 3methylindole (skatole) in faeces of various species. J Chromatogr. (1991) 566:101-7. doi: 10.1016/0378-4347(91)80114-R

20. Candek-Potokar M, Škrlep M, Batorek Lukač N, Zamaratskaia G, Prevolnik Povše M, Velikonja Bolta $\check{S}$, et al. Hydrolysable tannin fed to entire male pigs affects intestinal production, tissue deposition and hepatic clearance of skatole. Vet J. (2015) 204:162-7. doi: 10.1016/j.tvjl.2015.02.012

21. Bilić-Šobot D, Kubale V, Škrlep M, Candek-Potokar M, Prevolnik Povše M, Fazarinc G, et al. Effect of hydrolysable tannins on intestinal morphology, proliferation and apoptosis in entire male pigs. Arch Anim Nutr. (2016) 70:378-88. doi: 10.1080/1745039X.2016.1206735

22. Ratkowski DA. Nonlinear Regression Modelling. New-York, NY: Marcel Dekker Inc. (1983).

23. Quiniou N, Noblet J. Effect of the dietary net energy concentration on feed intake and performance of growing-finishing pigs housed individualy. J Anim Sci. (2012) 90:4362-72. doi: 10.2527/jas.2011-4004

24. Dunshea FR, Allison JRD, Bertram M, Boler DD, Brossard L, Campbell R, et al. The effect of immunization against GnRF on nutrient requirements of male pigs: a review. Animal. (2013) 7:1769-78. doi: 10.1017/S17517311130 01407

25. Batorek-Lukač N, Dubois S, Noblet J, Candek-Potokar M, Labussière E. Effect of high dietary fat content on heat production and lipid and protein deposition in growing immunocastrated male pigs. Animal. (2016) 10:19418. doi: $10.1017 /$ S1751731116000719

26. Labussière E, Dubois S, van Milgen J, Noblet J. Partitioning of heat production in growing pigs as a tool to improve the determination of efficiency of energy utilization. Front Physiol. (2013) 4:146. doi: 10.3389/fphys.2013. 00146

27. Kubale V, Batorek N, Škrlep M, Prunier A, Bonneau M, Fazarinc G, et al. Steroid hormones, boar taint compounds, and reproductive organs in pigs according to the delay between immunocastration and slaughter. Theriogenology. (2013) 79:69-80. doi: 10.1016/j.theriogenology.2012.09.010

28. Le Goff G, Noblet J. Comparative total tract digestibility of dietary energy and nutrients in growing pigs and adult sows. J Anim Sci. (2001) 79:241827. doi: $10.2527 / 2001.7992418 \mathrm{x}$ 
29. Noblet J, Shi XS. Comparative digestibility of energy and nutrients in growing pigs fed ad libitum and adult sows fed at maintenance. Livest Prod Sci. (1993) 34:137-52. doi: 10.1016/0301-6226(93)90042-G

30. Wilfart A, Montagne L, Simmins PH, van Milgen J, Noblet J. Sites of nutrient digestion in growing pigs: effect of dietary fiber. J Anim Sci. (2007) 85:97683. doi: $10.2527 /$ jas.2006- 431

31. Le Goff G, Dubois S, van Milgen J, Noblet J. Influence of dietary fibre level on digestive and metabolic utilisation of energy in growing and finishing pigs. Anim Res. (2002) 51:245-59. doi: 10.1051/animres:20 02019

32. Jha R, Fouhse JM, Tiwari UP, Li L, Willing BP. Dietary fiber and intestinal health of monogastric animals. Front Vet Sci. (2019) 6:48. doi: $10.3389 /$ fvets. 2019.00048

33. Bach Knudsen KE. Microbial degradation of whole-grain complex carbohydrates and impact on short-chain fatty acids and health. Adv Nutr. (2015) 6:206-13. doi: 10.3945/an.114.007450

34. Varel VH, Yen JT. Microbial perspective on fiber utilization by swine. J Anim Sci. (1997) 75:2715-22. doi: 10.2527/1997.75102715x

35. Armstrong D. Evaluvation of artificially dried grass as a source of energy for sheep:II. the energy value of cocksfoot, timothy and two strains of rye-grass at varying stages of maturity. J Agric Sci. (1964) 62:399416. doi: $10.1017 /$ S0021859600042507

36. Jin L, Reynolds LP, Redmer DA, Caton JS, Crenshaw JD. Effects of dietary fiber on intestinal growth, cell proliferation, and morphology in growing pigs. J Anim Sci. (1994) 72:2270-8. doi: 10.2527/1994.7292270x

37. Jha R, Rossnagel B, Pieper R, Van Kessel A, Leterme P. Barley and oat cultivars with diverse carbohydrate composition alter ileal and total tract nutrient digestibility and fermentation metabolites in weaned piglets. Animal. (2010) 4:724-31. doi: 10.1017/S1751731109991510

38. Pieper R, Jha R, Rossnagel B, Van Kessel AG, Souffrant WB, Leterme P. Effect of barley and oat cultivars with different carbohydrate compositions on the intestinal bacterial communities in weaned piglets. FEMS Microbiol Ecol. (2008) 66:556-66. doi: 10.1111/j.1574-6941.2008.00605.x

39. Li CY, Liu JX, Wang YZ, Wu YM, Wang JK, Zhou YY. Influence of differing carbohydrate sources on 1-tryptophan metabolism by porcine fecal microbiota studied in vitro. Livest Sci. (2009) 120:43-50. doi: 10.1016/j.livsci.2008.04.014

40. Zamaratskaia G, Squires EJ. Biochemical, nutritional and genetic effects on boar taint in entire male pigs. Animal. (2009) 3:1508-21. doi: 10.1017/S1751731108003674

41. Jha R, Berrocoso JD. Review: dietary fiber utilization and its effects on physiological functions and gut health of swine. Animal. (2015) 9:144152. doi: $10.1017 / \mathrm{S} 1751731115000919$

42. Claus R, Weiler U, Herzog A. Physiological aspects of androstenone and skatole formation in the boar-a review with experimental data. Meat Sci. (1994) 38:289-305. doi: 10.1016/0309-1740(94)90118-X

43. Bach Knudsen KE, Jensen BB, Hansen I. Digestion of polysaccharides and other major components in the small and large intestine of pigs fed on diets consisting of oat fractions rich in $\beta$-D-glucan. Br J Nutr. (1993) 7:53756. doi: 10.1079/BJN19930147

44. Jensen MT, Cox RP, Jensen BB. 3-Methylindole (skatole) and indole production by mixed populations of pig fecal bacteria. Appl Environ Microb. (1995) 61:3180-4. doi: 10.1128/aem.61.8.3180-3184.1995

45. Chen G, Zamaratskaia G, Andersson HK, Lundström K. Effects of raw potato starch and live weight on fat and plasma skatole, indole and androstenone levels measured by different methods in entire male pigs. Food Chem. (2007) 101:439-48. doi: 10.1016/j.foodchem.2005.11.054

46. Henry Y. Dietary factors involved in feed intake regulation in growing pigs: a review. Livest Prod Sci. (1985) 12:339-54. doi: 10.1016/0301-6226(85)90133-2

47. Li H, Yin J, Tan B, Chen J, Zhang H, Li Z, et al. Physiological function and application of dietary fiber in pig nutrition: a review. Anim Nutr. (2021) 7:259-67. doi: 10.1016/j.aninu.2020.11.011
48. Poklukar K, Candek-Potokar M, Vrecl M, Batorek-Lukač N, Fazarinc G, Kress K, et al. The effect of immunocastration on adipose tissue deposition and composition in pigs. Animal. (2021) 15:100118. doi: 10.1016/j.animal.2020.100118

49. Zeng XY, Turkstra JA, Jongbloed AW, van Diepen JTHM, Meloen RH, Oonk HB, et al. Performance and hormone levels of immunocastrated, surgically castrated and intact male pigs fed ad libitum high- and lowenergy diets. Livest Prod Sci. (2002) 77:1-11. doi: 10.1016/S0301-6226(02) 00024-6

50. Len NT, Lindberg JE, Ogle B. Effect of dietary fiber level on the performance and carcass traits of mong cai, F1 crossbred (mong caixyorkshire) and landracexyorkshire pigs. Asian Australas J Anim Sci. (2008) 21:24551. doi: 10.5713/ajas.2008.60598

51. de Leeuw JA, Bolhuis JE, Bosch G, Gerrits WJ. Effects of dietary fibre on behaviour and satiety in pigs. Proc Nutr Soc. (2008) 67:33442. doi: $10.1017 / \mathrm{S} 002966510800863 \mathrm{X}$

52. Byrne CS, Chambers ES, Morrison DJ, Frost G. The role of short chain fatty acids in appetite regulation and energy homeostasis. Int J Obes. (2015) 39:1331-8. doi: 10.1038/ijo.2015.84

53. Noblet J, van Milgen J. Energy value of pig feeds: effect of pig body weight and energy evaluation system. J Anim Sci. (2004) 82:E22938. doi: 10.2527/2004.8213_supplE229x

54. Cisneros F, Ellis M, McKeith FK, McCaw J, Fernando RL. Influence of slaughter weight on growth and carcass characteristics, commercial cutting and curing yields, and meat quality of barrows and gilts from two genotypes. J Anim Sci. (1996) 75:925-33. doi: 10.2527/1996.745925x

55. Warriss P. Meat Science $2^{\text {nd }} e d$. Bristol:CABI (2010).

56. Jones S. Growth of meat animals: Growth patterns. In: Jensen WK, Devine C, Dikeman M, editors. Encyclopedia of Meat Sciences. Oxford: Elsevier Academic Press (2004). p. 506-11. doi: 10.1016/B0-12-464970-X/00015-5

57. Kouba M, Bonneau M. Compared development of intermuscular and subcutaneous fat in carcass and primal cuts of growing pigs from 30 to $140 \mathrm{~kg}$ body weight. Meat Sci. (2009) 81:270-4. doi: 10.1016/j.meatsci.2008.08.001

58. Kouba M, Sellier P. A review of the factors influencing the development of intermuscular adipose tissue in the growing pig. Meat Sci. (2011) 88:21320. doi: 10.1016/j.meatsci.2011.01.003

59. dos Santos AP, Kiefer C, Martins LP, Fantini CC. Feeding restriction to finishing barrows and immunocastrated swine. Cienc Rural. (2012) 42:14753. doi: $10.1590 /$ S0103-84782012000100024

Conflict of Interest: The authors declare that the research was conducted in the absence of any commercial or financial relationships that could be construed as a potential conflict of interest.

The reviewer DK declared a past co-authorship with several of the authors, MČ-P, MS, and NB-L, to the handling editor.

Publisher's Note: All claims expressed in this article are solely those of the authors and do not necessarily represent those of their affiliated organizations, or those of the publisher, the editors and the reviewers. Any product that may be evaluated in this article, or claim that may be made by its manufacturer, is not guaranteed or endorsed by the publisher.

Copyright $\odot 2021$ Batorek-Lukač, Čandek-Potokar, Škrlep, Kubale and Labussière. This is an open-access article distributed under the terms of the Creative Commons Attribution License (CC BY). The use, distribution or reproduction in other forums is permitted, provided the original author(s) and the copyright owner(s) are credited and that the original publication in this journal is cited, in accordance with accepted academic practice. No use, distribution or reproduction is permitted which does not comply with these terms. 